\title{
Sea-level rise in Denmark: bridging local reconstructions and global projections
}

\author{
William Colgan*1, Jason E. Box ${ }^{1}$, Sofia Ribeiro ${ }^{1}$ and Kristian K. Kjeldsen ${ }^{1}$
}

RESEARCH ARTICLE | OPEN ACCESS

GEUS Bulletin Vol 43 | e2019430101 | Published online: 01 July 2019

https://doi.org/10.34194/GEUSB-201943-01-01

Between 1850 and 2006 global mean sea level rose by $24 \pm$ $18 \mathrm{~cm}$. It is projected to rise a further $52 \pm 21 \mathrm{~cm}$ under the Representative Concentration Pathway (RCP) 4.5 scenario, which approximates the carbon emissions reductions of the 'Paris Agreement' climate pathway. It is projected to rise $74 \pm$ $28 \mathrm{~cm}$ under the RCP8.5 scenario, which represents a 'business-as-usual' climate pathway (Box \& Colgan 2017). These rates of recent and future sea-level rise are faster than those reconstructed for previous warm intervals, such as the Medieval Climatic Optimum (c. 1000 to $1400 \mathrm{CE}$ ) and the Holocene Thermal Maximum (c. 7000 to 3000 BCE) (Gehrels \& Shennan 2015). Moreover, palaeo reconstructions indicate a global sea-level sensitivity of two metres per degree of warming (Levermann et al. 2013).

The forces driving global sea-level change are complex. The global sea-level budget includes the transfer of land ice into the ocean, thermal expansion of seawater, changes in land water storage, and changes in ocean basin volume (Church et al. 2013). At the local scale, the evolving planetary gravity due to shifting water and ice masses, shifting oceanic and atmospheric currents and persistent tectonic and glacial isostatic adjustment processes can also be important. Sea-level changes around the globe are therefore far from uniform (Jevrejeva et al. 2016).

Here, we highlight the value of combining palaeo reconstructions of sea level, the measured tide gauge record, and projections of future sea level. This allows us to understand local sea-level changes from the recent past in the context of global projections for the near future (0 to $2100 \mathrm{CE}$ ). We explore the strong differences in local sea-level histories and future projections at three Danish cities: Skagen and Esbjerg, as they have contrasting glacio-isostatic adjustment histories, and Copenhagen, where we also compare local and global drivers of present-day sea-level rise based on previously published research.

\section{Data}

We employ the standardised Permanent Service for Mean Sea Level annual tide gauge records at Copenhagen (PSMSL site 21), Esbjerg (PSMSL site 80) and Skagen (PSMSL site 89) since $c .1880$ (Holgate et al. 2013). While PSMSL data are formatted as sea-level elevation relative to the geoid, we instead express local sea-level elevations as relative to the 1901-1950 baseline elevation throughout this study (Fig. 1). For each city, we characterise a centennial (1900-1999) rate of sea-level change using a linear trend to the annual PSMSL data. We estimate uncertainty in this centennial sea-level trend using a Monte Carlo envelope that assumes $\pm 10 \mathrm{~cm}$ uncertainty in annual elevations.

The dating of raised beach sequences, wind-blown sand deposits, and salt-marsh sediments has permitted sea level to be reconstructed since the last glaciation at Skagen (Hauerbach 1992; Clemmensen et al. 2001) and Esbjerg (Gehrels et al. 2006; Szkornik et al. 2008). At Esbjerg, the palaeo records of relative sea level overlap with the observed record of tide gauge data, revealing some discrepancies between the two datasets during this overlapping period. For example, Gehrels et al. (2006) suggest palaeo-sea-level at Esbjerg in the 1880s was $-24 \mathrm{~cm}$ below the $c .2000$ level, while the tide gauge record suggests it was $-5 \mathrm{~cm}$ below the 1901-1950 baseline. Some of this apparent discrepancy is likely attributable to differing baseline periods in the two datasets. To minimise such discrepancies, we shift the relative sea levels reported in Gehrels et al. (2006) and Szkornik et al. (2008) by +19 and $-8 \mathrm{~cm}$, respectively. At Skagen, there is no overlap of measured tide gauge data and reconstructed sea levels. We therefore assume the relative sea levels reported in Hauerbach (1992) and Clemmensen et al. (2001) are characteristic of the 1901-1950 reference period. Analogous palaeo reconstructions of sea-level elevation are not readily available in the immediate vicinity of Copenhagen, reflecting the relative paucity of palaeo data within urbanised Sjælland. 
A
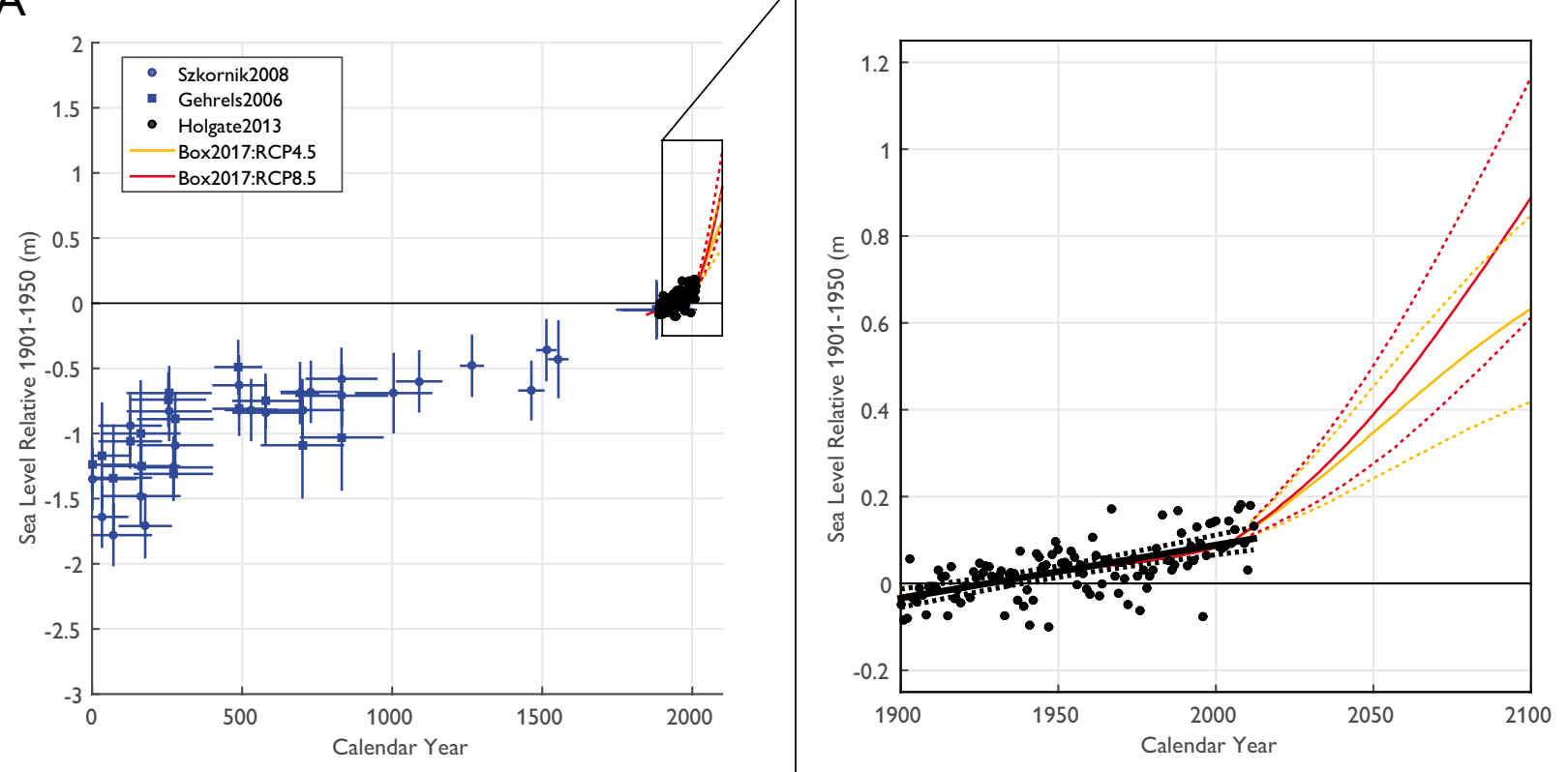

B
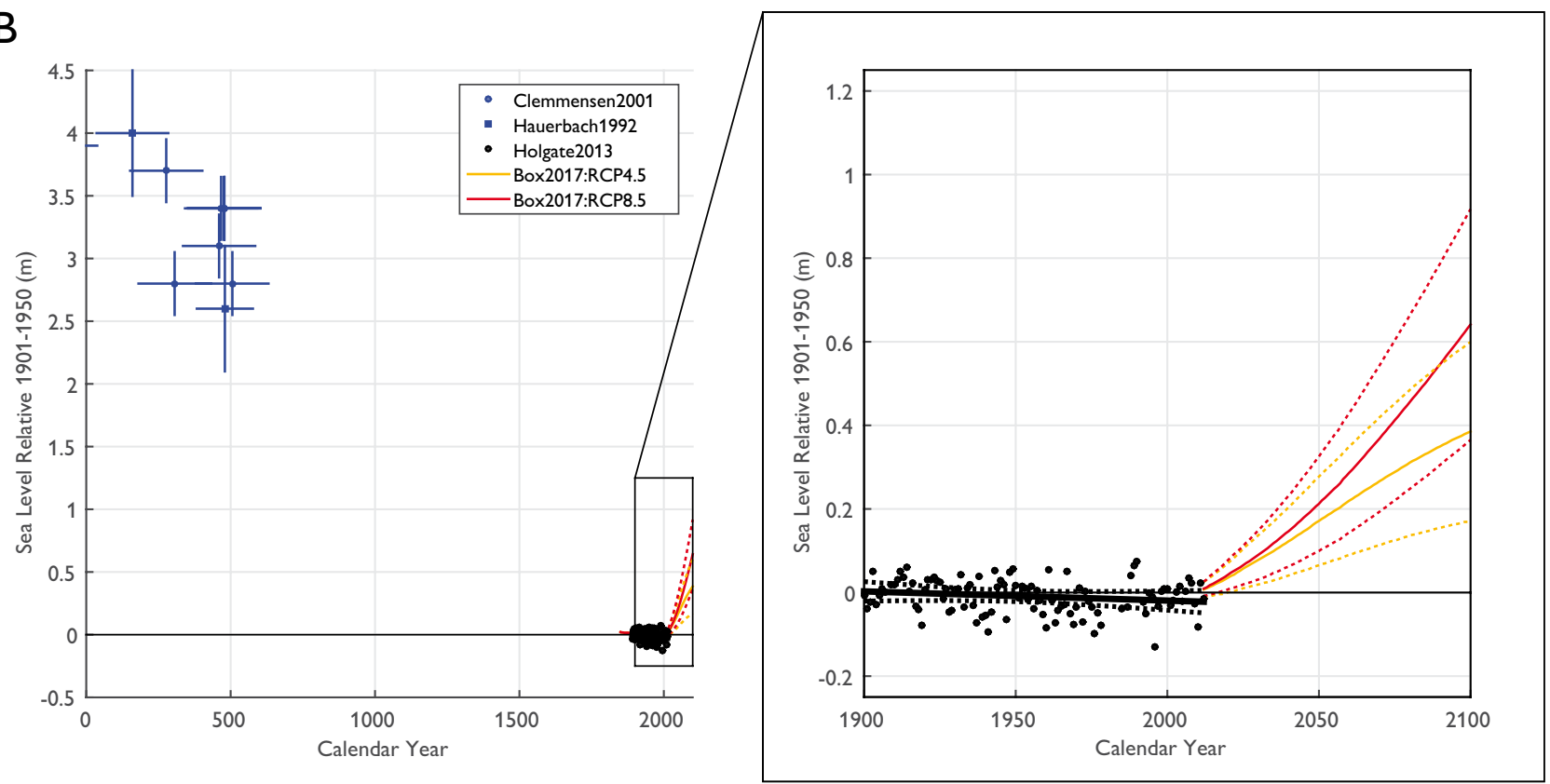

Fig. 1. Sea level, relative to the 1901-1950 period, at Esbjerg (A) and Skagen (B) between 0 and 2100 CE, derived from palaeo reconstructions (Hauerbach 1992; Clemmensen et al. 2001; Gehrels et al. 2006; Szkornik et al. 2008), tide gauge measurements (Holgate et al. 2013) and projections (Box \& Colgan 2017). For palaeo reconstructions, uncertainty is depicted with $\mathrm{x}$ - and $\mathrm{y}$-whiskers. For projections, uncertainty is depicted with dashed lines bounding solid line best estimates. Linear best fit and associated uncertainty is shown for the tide gauge records.

The projections of future sea-level rise are based on simulations of global sea-level budget terms under the RCP4.5 and RCP8.5 climate pathways (Box \& Colgan 2017). We translate this 1850-2100 global eustatic sea-level budget into local sea-level budgets by applying a linear trend to the global budget that makes it fit the linear trend of a local budget during the 20th century (1900-1999). This yields global-to-local scaling terms of $0.4 \mathrm{~mm} /$ year at Esbjerg, -1.8 $\mathrm{mm} /$ year at Skagen and $1.1 \mathrm{~mm} /$ year at Copenhagen. These terms capture the site-specific processes causing deviations from the global mean - including the net effects of glacioisostatic adjustment and persistent changes in atmospheric and oceanic currents - during the 20th century. These linear scaling terms are also applied to the projections. 


\section{Past millennial-scale sea-level change}

In the past 2000 years, local relative sea level has risen $1.5 \pm$ $0.5 \mathrm{~m}(0.8 \pm 0.3 \mathrm{~mm} /$ year $)$ at Esbjerg and fallen $4.0 \pm 0.5 \mathrm{~m}$ $(2.0 \pm 0.3 \mathrm{~mm} /$ year) at Skagen (Table 1). These contrasting sea-level histories are primarily due to local differences in glacio-isostatic adjustment. At Skagen, the Earth's crust is still rebounding upwards following the relatively rapid removal of the Scandinavian ice sheet during the last glaciation $c$. 17000 years ago (Morén et al. 2018). At Esbjerg, the Earth's crust is still sinking due to the collapse of the crustal forebulge that once ringed the Scandinavian ice sheet (Stuhne \& Peltier 2015; Fig. 2). Local relative sea-level rise reflects the net effect of changes in land and ocean elevation.

During the 20th century, Skagen was rebounding faster than eustatic sea level was rising. As a result, while global average sea level rose $1.5 \pm 0.4 \mathrm{~mm}$ /year during 1900-1999 (Box \& Colgan 2017), the relative sea level measured at Skagen fell $0.3 \pm 0.4 \mathrm{~mm} /$ year (Holgate et al. 2013). At Esbjerg, sea level did rise, but less than the global mean $(1.1 \pm 0.4 \mathrm{~mm} /$ year). These local departures from the global pattern reflect our global-to-linear scaling terms described above. Assessing the magnitude and spatial distribution of recent sea-level rise across Denmark therefore requires - among other things constraining present-day glacio-isostatic adjustment rates resulting from deglaciation following the last glacial period.

\section{Present-day sea-level rise components}

Land ice was responsible for $c .51 \%$ of global mean sea-level rise during 2004-2010 (Box \& Colgan 2017). As large ice and water masses shift around the planet, they modify the planetary gravity field. Where land ice diminishes under climate change, local gravitational fields weaken and nearby sea level falls. In this process, the ocean water previously held near land ice is redistributed to raise distant sea levels, elsewhere. In this way, Greenland land ice contributes four times as much to global mean sea-level rise (c. 24\%) than it does to local sea-level rise at Copenhagen (c. 6\%; Fig. 3). Conversely, Antarctic land ice is slightly more important to local sea-level rise at Copenhagen (c. 11\%) than the global mean (c. 7\%). This is because Copenhagen lies within the gravitational weakening anomaly associated with Greenland, but lies outside the analogous gravitational weakening anomaly associated with Antarctica (Larour et al. 2017).

Notably, while Scandinavian land ice contributes just $c$. $1 \%$ global mean sea-level rise, it actually provides a c. $1 \%$ sealevel fall at Copenhagen due to the associated weakening of gravity within Scandinavia (Larour et al. 2017). Non-land ice processes, including the thermal expansion of seawater, changes in land water storage (i.e. groundwater and dams) and - at the local scale - shifts in atmospheric and oceanic currents, are relatively more important to local sea-level rise at Copenhagen (c. 69\%) than the global mean (c. 49\%). Post1993 satellite altimetry indicates that sea level is increasing in the Gulf of Bothnia, between Finland and Sweden, more than three times faster than in the North Sea (Fig. 2). Moreover, appreciable local glacio-isostatic adjustment rates mean that global sea-level budget terms cannot be neatly translated into local sea-level budget terms (Nielsen et al. 2014).

\section{Sea-level rise projections}

While the city-specific sea-level projections we present here are less physically-based than those derived from more complex downscaling approaches (Jevrejeva et al. 2016), they are informative within their respective one standard deviation
A

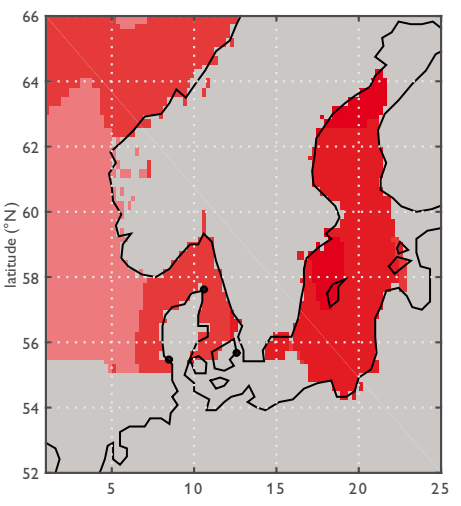

B

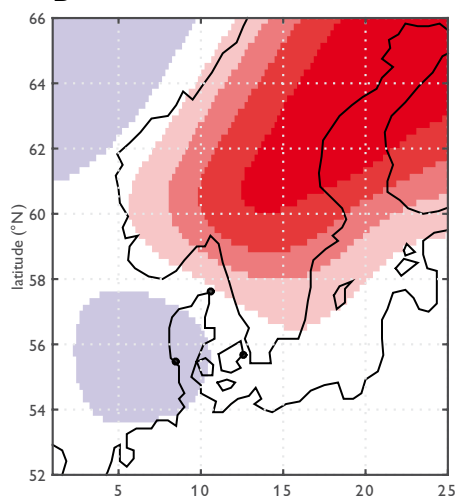

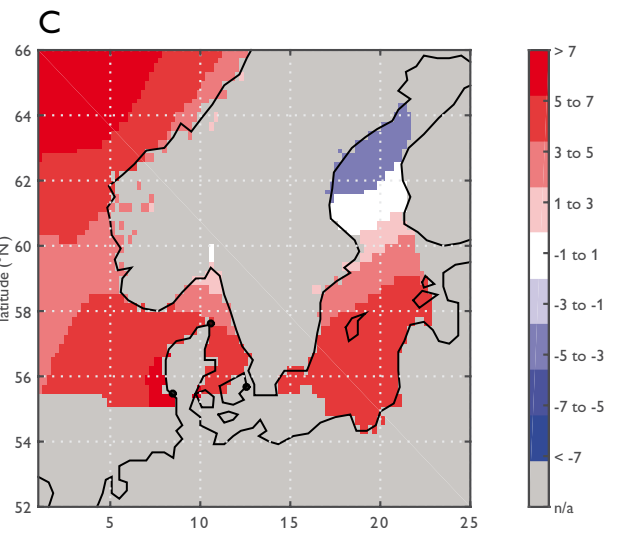

Fig. 2 A: Trend in mean sea-level elevation (in mm/year) measured by satellite altimetry during the January 1993 and July 2016 period for which data were freely available (Nerem et al. 2010). B: Present-day (c. 2015) glacio-isostatic rebound (in mm/year) simulated by one of the many geodynamic models for which data were freely available (Stuhne \& Peltier 2015). C: Relative sea-level change calculated as A minus B, without accounting for geoid differences between both datasets. 

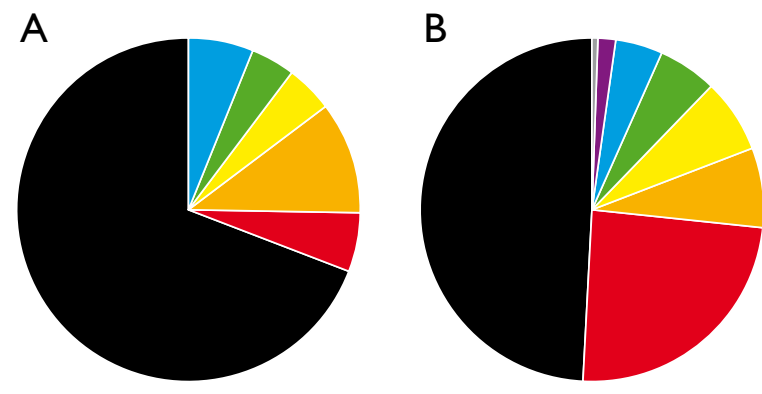

- Russian Arctic land ice

- Scandinavian land ice

- Alaskan land ice

- Canadian Arctic land ice

Other land ice

Antarctic land ice

- Greenland land ice

- Non-land ice processes
Fig. 3. Highlighting the present-day land ice contribution to sea-level rise at Copenhagen (A) and the global mean (B) (Box \& Colgan 2017; Larour et al. 2017). The slight difference in pie chart size reflects sea-level rise at Copenhagen $(2.9 \pm 0.4 \mathrm{~mm} /$ year; Holgate et al. 2013) versus the global mean $(2.8 \pm$ $0.3 \mathrm{~mm} /$ year; Nerem et al. 2010) during the 1993-2012 period. Non-land ice processes include thermal expansion of seawater, changes in land water storage and shifts in atmospheric and oceanic currents at the local scale. uncertainties. The distance between Esbjerg and Skagen $280 \mathrm{~km}$ - highlights a considerable spatial gradient in sealevel rise. Due to ongoing glacio-isostatic rebound at Skagen, 21 st century sea-level rise relative to 1901-1950 will be limited to $64 \pm 28 \mathrm{~cm}$ under RCP8.5 and $39 \pm 21 \mathrm{~cm}$ under RCP4.5 (Table 1). At Esbjerg, where there is instead ongoing glacio-isostatic subsidence, 21 st century sea-level rise will consequently be $c .25 \mathrm{~cm}$ greater; $89 \pm 28 \mathrm{~cm}$ under RCP8.5 and $63 \pm 21 \mathrm{~cm}$ under RCP4.5. The year 2100 sea-level rise projected for Esbjerg under RCP4.5 is therefore similar to that projected for Skagen under RCP 8.5. The sea-level forecast for Copenhagen is between that of these two endmember case studies. At all three cities, rates of 21 st century sea-level rise will be ten times more rapid than rates of 20 th century sea-level rise. At Esbjerg, the sea-level change over the next century will be approximately equivalent in magnitude to the sea-level change that has occurred there over the past millennium.

Table 1. Sea level $(\mathrm{m})$ relative to the 1901-1950 mean at Skagen, Copenhagen and Esbjerg between 0 and 2100 CE based on palaeoreconstructions, tide gauge measurements and projections.

\begin{tabular}{llccc}
\hline Year & & Skagen & Copenhagen & Esbjerg \\
& & & & \\
\hline c. 0 & & $4.0 \pm 0.5$ & $\mathrm{n} / \mathrm{a}$ & $-1.5 \pm 0.5$ \\
1980 & & $-0.01 \pm 0.01$ & $0.01 \pm 0.01$ & $0.06 \pm 0.01$ \\
2010 & & $-0.02 \pm 0.01$ & $0.02 \pm 0.01$ & $0.10 \pm 0.01$ \\
2040 & RCP4.5 & $0.12 \pm 0.08$ & $0.21 \pm 0.08$ & $0.28 \pm 0.08$ \\
& RCP8.5 & $0.15 \pm 0.09$ & $0.23 \pm 0.09$ & $0.31 \pm 0.09$ \\
2070 & RCP4.5 & $0.27 \pm 0.15$ & $0.37 \pm 0.15$ & $0.47 \pm 0.15$ \\
& RCP8.5 & $0.37 \pm 0.18$ & $0.47 \pm 0.18$ & $0.57 \pm 0.18$ \\
2100 & RCP4.5 & $0.39 \pm 0.21$ & $0.51 \pm 0.21$ & $0.63 \pm 0.21$ \\
& RCP8.5 & $0.64 \pm 0.28$ & $0.77 \pm 0.28$ & $0.89 \pm 0.28$ \\
\hline
\end{tabular}

Uncertainties denote one standard deviation.

\section{Outlook}

This study translates the global sea-level projections compiled by the Geological Survey of Denmark and Greenland (GEUS) in support of the 2017 Snow, Water, Ice and Permafrost Assessment of the Arctic Monitoring (SWIPA 2017) and Assessment Program into local sea-level rise projections at Esbjerg, Skagen and Copenhagen. These Danish case studies highlight strong differences in local sea-level histories and projections, as well as marked differences in the drivers of present-day sea-level rise relative to the global average. There is a multi-centennial to millennial lag in the global sea-level response to global climate, which can introduce transient local sea-level responses. Contextualising near-term change with long-term perspectives can therefore substantially improve local sea-level projections.

Contemporary sea-level change is variable across the Earth. This study supports ongoing efforts by the Department of Glaciology and Climate at GEUS to communicate emerging sea-level science to the Danish public in a local and regional context, especially with regard to the role of the changing Greenland ice sheet (Colgan et al. 2018). Here, we show that the year 2100 differences in projected sea-level rise between two Danish cities under a single climate scenario is approximately equivalent to the differences projected for one city under two climate scenarios. Communicating presentday and future sea-level changes throughout the Kingdom of Denmark - including Greenland and the Faroe Islands - therefore remains a challenging task.

\section{References}

Box, J. \& Colgan, W. 2017: Sea level rise contribution from Arctic land ice: 1850-2100. In: Snow, Water, Ice and Permafrost in the Arctic (SWIPA) 2017, 219-229. Arctic Monitoring and Assessment Programme (AMAP), Oslo, Norway.

Church, J. et al. 2013: Sea Level Change. In: Climate Change 2013: The Physical Science Basis. Contribution of Working Group I to the 
Fifth Assessment Report of the Intergovernmental Panel on Climate Change, 1137-1205, Cambridge, Cambridge University Press. https:// doi.org/10.1017/CBO9781107415324.026

Colgan, W., Grinsted, A., Box, J. \& MacFerrin, M. 2018: The mind-bending physics of Scandinavian sea-level change. Popular science article for ScienceNordic.com and Videnskab.dk: http://sciencenordic.com/ mind-bending-physics-scandinavian-sea-level-change

Clemmensen, L., Richardt, N. \& Andersen, C. 2001: Holocene sea-level variation and spit development: data from Skagen Odde, Denmark. The Holocene 11, 323-331. http://dx.doi. org/10.1191/095968301667877044

Gehrels, W., Szkomik, K., Bartholdy, J., Kirby, J., Bradley, S., Marshall, W., Heinemeier, J. \& Pedersen, J. 2006: Late Holocene sea-level changes and isostasy in western Denmark. Quaternary Research 66, 288-302. http://dx.doi.org/10.1016/j.yqres.2006.05.004

Gehrels, W. \& Shennan, I. 2015: Sea level in time and space: Revolutions and inconvenient truths. Journal of Quaternary Science 30, 131-143. http://dx.doi.org/10.1002/jqs.2771

Hauerbach, P. 1992: Skagen Odde - Skaw Spit. An area of land created between two seas. Folia Geographica Danica 20, 119 pp.

Holgate, S. et al. 2013: New Data Systems and Products at the Permanent Service for Mean Sea Level. Journal of Coastal Research 29, 493-504. http://dx.doi.org/10.2112/jcoastres-d-12-00175.1

Jevrejeva, S., Jackson, L., Riva, R., Grinsted, A. \& Moore, J. 2016: Coastal sea level rise with warming above $2^{\circ} \mathrm{C}$. Proceedings of the National Academy of Sciences 113, 13342-13347. https://doi.org/10.1073/ pnas. 1605312113

Larour, E., Ivins, E. \& Adhikari. S. 2017: Should coastal planners have concern over where land ice is melting? Science Advances 3, p.e1700537. http://dx.doi.org/10.1126/sciadv.1700537.

Levermann, A., Clark, P., Marzeion, B., Milne, G., Pollard, D., Radic, V. \& Robinson, A. 2013: The multimillennial sea-level commitment of global warming. Proceedings of the National Academy of Sciences 110, 13745-13750. https://doi.org/10.1073/pnas.1219414110
Móren, B., Sejrup, H., Hjestuen, B., Borge, M. \& Schaüble, C. 2018: The last deglaciation of the Norwegian Channel - geomorphology, stratigraphy and radiocarbon dating. Boreas 47, 347-366. http://dx.doi. org/10.1111/bor. 12272

Nerem, R., Chambers, D., Choe, C. \& Mitchum, G. 2010: Estimating Mean Sea Level Change from the TOPEX and Jason Altimeter Missions. Marine Geodesy 33, 435-446. http://dx.doi.org/10.1080/0149 0419.2010.491031

Nielsen, L., Hansen, J., Hede, M., Clemmensen, L., Pejrup, M. \& NoeNygaard, N. 2014: Simultaneous estimation of lithospheric uplift rates and absolute sea level change in southwest Scandinavia from inversion of sea level data. Geophysics Journal International 199, 1018-1029. http://dx.doi.org/10.1093/gji/ggu290

Permanent Service for Mean Sea Level (PSMSL) 2018: Tide Gauge Data. Retrieved 10 November 2018 from http://www.psmsl.org/data/obtaining.

Stuhne, G. \& Peltier, W. 2015: Reconciling the ICE-6G_C reconstruction of glacial chronology with ice sheet dynamics: The cases of Greenland and Antarctica. Journal of Geophysical Research: Earth Surface 120, 1841-1865. http://dx.doi.org/10.1002/2015jf003580

Szkornik, K., Gehrels, W. \& Murray, A. 2008: Aeolian sand movement and relative sea-level rise in Ho Bugt, western Denmark, during the 'Little Ice Age'. The Holocene 18, 951-965. https://doi. org/10.1177/0959683608091800

\section{How to cite}

Colgan, W., Box, J.E., Ribeiro, S. \& Kjeldsen, K.K. 2019: Sea-level rise in Denmark: Bridging local reconstructions and global projections. Geological Survey of Denmark and Greenland Bulletin 43, e2019430101. https://doi.org/10.34194/GEUSB-201943-01-01 